\title{
Research of Distribution Network Intelligent Reconstruction Based on Energy Management Contracting
}

\author{
Luo fan ${ }^{1}$, Zhang Jianhua ${ }^{2}$, Han Yongjun ${ }^{2, a^{*}}$, Wang Weizhou ${ }^{2}$, \\ Zheng Jingjing ${ }^{2}$ \\ ${ }^{1}$ Gansu Electric Power CO. Gansu Lanzhou, China 730000 \\ ${ }^{2}$ State Grid Gansu Electric Power Research Institute. Gansu Lanzhou, China 730050 \\ aemail: hyjlcf@163.com
}

\begin{abstract}
Keywords: energy management contracting; distribution network reconstruction; energy saving in power grid enterprises

Abstract. This paper, by comparing the existing problems of distribution network technical transformation and the advantages of energy management contracting, puts forward the necessity of the implementation of energy management contracting mode of distribution network transformation of the power grid enterprises, the specific operation mode of power grid technological transformation projects which energy saving company invests in, and gives an example that energy saving company invests in Gansu distribution network reconstruction project, sharing their experience and demonstration effect. It provides the references to construction and operation of similar projects and has the application value.
\end{abstract}

\section{Introduction}

Distribution network is in responsible for the transmission of electricity to the power users ${ }^{[1,2]}$. Distribution network construction's most basic responsibility and obligation are delivering the power to the users safely and efficiently. Currently, there are some phenomena existing universally, such as high public distribution transformer load fluctuations, unbalanced three-phase load, low voltage qualification rate, low degree of automation, high rate of line loss, lack of reactive power compensation capacity, irrational layout and structure of the distribution network, and so on. Now the power grid enterprises upgrade the distribution network commonly by the mode of technical transformation and overhaul, which is by issuing the funds of technical transformation and overhaul, and the city companies carry on distribution network reconstruction. With the strengthen of management measures and introduction of scientific management methods like ERP, project management of technical transformation and overhaul has become increasingly rigorous and standardized. But there are still some problems in the management and control process of practical project. This paper implements distribution network intelligent reconstruction through the introduction of energy management contracting, and tests it by the practical project.

\section{Energy management contracting}

\section{Business model of energy management contracting}

The mechanism of energy management contracting is energy users pay all costs of energy saving reform through saving energy costs by energy saving reform. Before energy saving reform, clients need to undertake lots of energy costs and equipment operation and maintenance costs. While during the process of energy saving reform, ESCO's income comes from the part of client's energy costs by saving. And clients will gain all the energy-saving benefits after the accomplishment of energy saving reform. 


\section{Importance of power grid enterprises implementing energy management contracting}

Insignificance of the mode of power grid enterprises technical transformation and overhaul

The projects of technical transformation and overhaul are some technical measures such like that power grid enterprises maintain and fill their equipment and assets for promoting grid's sound development. However, the mode of power grid enterprises technical transformation and overhaul lacks realistic input-output analysis, and it influents the improvement of the economic efficiency of enterprises. And the reconstruction results lack real-time monitoring and statistics, it's harmful to further improve the distribution network operation and management level. Capital expenditures and revenue expenditures' confusion causes enterprises to face significant tax risks. At the same time the lack of funds leads to a lack of timely distribution network transformation and reduces the operation quality and reliability of the grid.

\section{Superiority of energy management contracting (EPC) mode}

From the social value, implementation of the energy management contracting can give full play to the professional advantages, also provide professional energy services and reduce losses for grid. From the enterprise value, power grid enterprises can significantly improve energy efficiency and create significant economic benefits by implementing energy management contracting. On the other hand, it can also rich the connotation of grid enterprises customer service work, improve service levels, enhance customer loyalty and win stability for the company's sustained and healthy development. From the management and control of projects, centralization of project implementation, unified management and professional services relieves the burden on customers in project management, technology and engineering, and reduces the main risks of energy efficiency projects.

\section{Evolutionary game model of energy consumption enterprises and energy saving company}

Table 2-1 Payoff matrix of game both parties

\begin{tabular}{|c|c|c|c|}
\hline \multirow{3}{*}{ 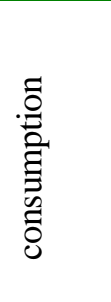 } & \multirow[b]{3}{*}{ Cooperation } & \multicolumn{2}{|c|}{ Energy saving company } \\
\hline & & Cooperation & Noncooperation \\
\hline & & $\pi_{f}+\Delta S_{f}, \pi_{g}+\Delta S_{g}$ & $\pi_{f}-l_{f} a_{f}, \pi_{g}$ \\
\hline 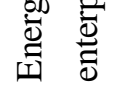 & Noncooperation & $\pi_{f}, \pi_{g}-l_{g} a_{g}$ & $\pi_{f}, \pi_{g}$ \\
\hline
\end{tabular}

In payoff matrix, $\pi_{f}$ represents energy consumption enterprises' gaining normal profit by taking noncooperation mode, and $\pi_{f}$ equals $\delta_{f}^{t-1} \Delta S_{f}$. The $\delta_{f}$ represents the discount factor of energy consumption enterprises, and $0 \leq \delta_{f}<1$. The $\pi_{\mathrm{g}}$ represents energy saving company's gaining normal profit by taking noncooperation mode, and $\pi_{\mathrm{g}}$ equals $\delta_{\mathrm{g}}^{t-1} \Delta S_{\mathrm{g}}$. The $\delta_{\mathrm{g}}$ represents the discount factor of energy saving company, and $0 \leq \delta_{\mathrm{g}}<1$. The $\Delta S_{f}$ represents the energy consumption enterprises' gaining superprofit by taking cooperation mode. The $\Delta S_{\mathrm{g}}$ represents energy saving company's gaining superprofit by taking cooperation mode. When the enterprises' income coefficient $\gamma_{f}$ and $\gamma_{\mathrm{g}}$ is larger, the superprofit making by cooperation is larger. 


\section{Specific operation mode of grid enterprises energy saving company's energy management contracting}

\section{Implementation process}

Grid enterprises' specialized energy service companies, through integrating of the technology, funds, equipments and personnel resources in the aspect of energy service within the grid enterprise, by the mode of energy management contracting, carry out the integration services of energy saving. Mainly on reactive power compensation, transformer economic operation and distribution network conservation and economic operation, continually accumulating experience, gradually extending the business to conversion, distributed power and other areas, energy service company becomes the formation of covering all professional and the integration of all kinds of energy saving technologies ${ }^{[3]}$.The distribution network intelligent reconstruction process of grid enterprises energy management contracting mode is shown in Figure 3-1.

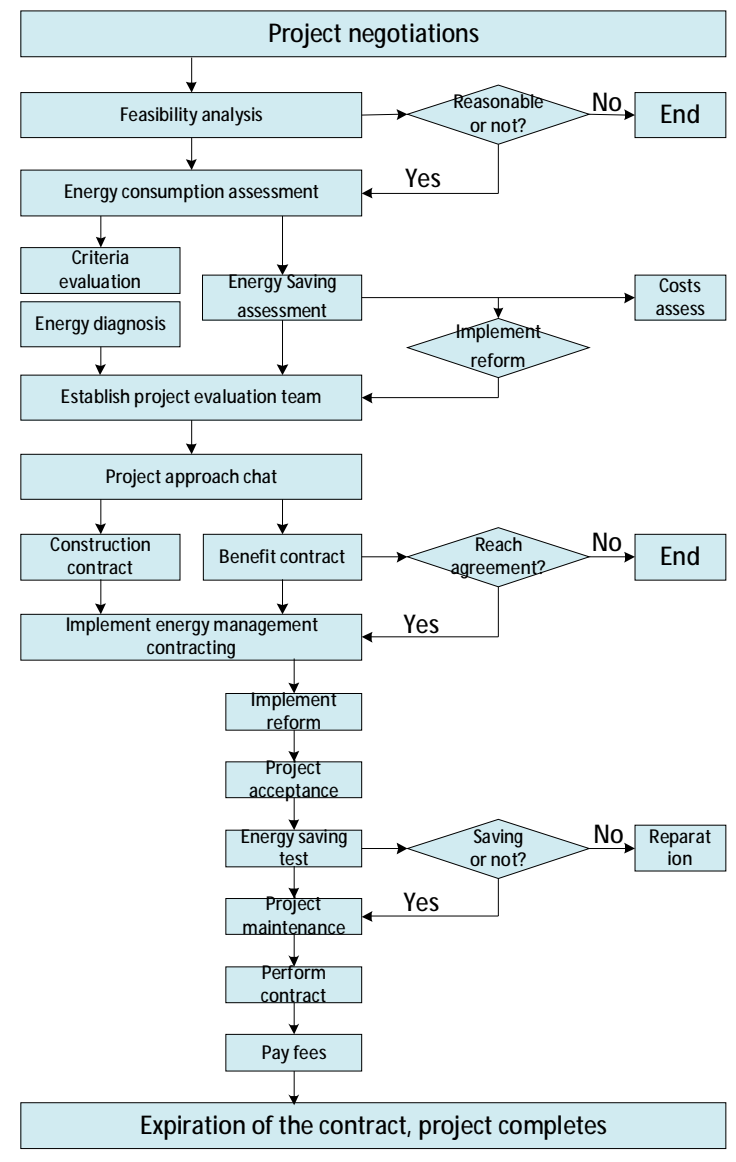

Figure 3-1. The distribution network intelligent reconstruction process of grid enterprises energy management contracting mode

\section{Key link}

The entire process of energy service companies implementing energy management contracting can be divided into two stages. The first stage is the research design and cooperation mode determining of the project. The second stage is the implementation and operation of the project. In these steps, there are three of the most important aspects impacting energy saving effect and efficiency, project selection before the implementation, evaluation of energy savings after the implementation and operational monitoring. 


\section{Empirical analysis}

\section{Project description}

Gansu distribution network energy saving and improve power quality renovation project (referred to as Gansu distribution network project) is funded and implemented by the State Grid energy company. Gansu Power Company implementation units are in charge of completion acceptance of the project and assets receiving after finishing contract. The contract period, the State Grid energy company shares 100 percent of the energy saving benefits. After the expiration of the contract, the project assets are transferred to the city power company without compensation. The specific process is shown in Figure 4-1.

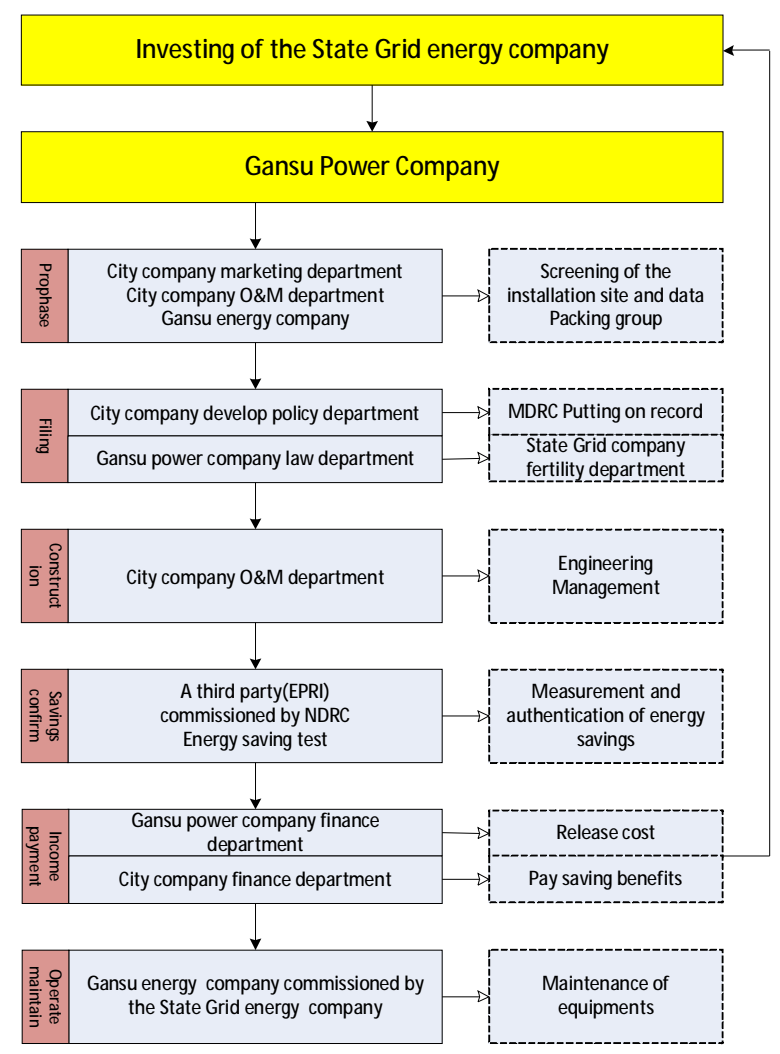

Figure 4-1. The flow chart of Gansu distribution network project implementation

\section{Key link control}

In the project, the three most important aspects are given the key control. The first is data filtering. After identifying in the screening conditions, we determine the scope of the project, ensure the reliability of the parameters and ensure the effectiveness of the project with the marketing system and reading system. The second is savings evaluation and confirmation. After completing this project, according to the evaluation method agreed in the contract, a third-party evaluation institution carries out the evaluation. And savings confirmation is the basis for bilateral settlement. Third, the project builds a distribution network energy management system at the same time. It realizes the integrated collection and monitoring of energy efficiency and energy consumption data in all aspects of grid. It constructs energy efficiency monitoring and management center, energy efficiency analysis and evaluation center, energy efficiency regulation and control center and energy efficiency advanced applications center. And other related business systems are data integrated. It builds a technical support platform of distribution network three rates and reducing energy loss, to prevent loss of control of the project at a later stage. And the data also provides a guarantee for the intelligence and informatization of the distribution network. 


\section{Energy saving benefits analysis}

The project installed 257 reactive power compensation, and the annual electricity savings reached a total of 3,194,500 $\mathrm{kWh}$, saved 1054.19 tons of standard coal and reduced carbon dioxide emissions 2740.89 tons. The energy saving effect is remarkable. After evaluation, the project achieved the expected results.

\section{Increase power}

Take the case of Qilihe LanTongbian 118 PengJiaping line smelter. Before compensation, the power factor was 0.82 . While after compensation, the power factor is 0.95 . The monthly electricity savings is $665.7 \mathrm{kWh}$, the monthly theoretical line loss rate has dropped by $23.9 \%$, and the maximum lift of installation point voltage is $8.63 \mathrm{~V}$.

Table 4-1. LanTongbian 118 PengJiaping line smelter low voltage reactive compensation effect comparison

\begin{tabular}{|c|c|c|c|c|c|}
\hline Name & \multicolumn{5}{|c|}{ LanTongbian 118 PengJiaping line smelter low voltage reactive compensation } \\
\hline $\begin{array}{l}\text { Reform } \\
\text { contents }\end{array}$ & \multicolumn{5}{|c|}{$\begin{array}{l}\text { Install low voltage reactive power compensation, improve power factor } \\
\text { Power factor is fixed at } 0.95\end{array}$} \\
\hline Costs & \multicolumn{5}{|c|}{15,000 yuan } \\
\hline $\begin{array}{l}\text { Recovery } \\
\text { period }\end{array}$ & \multicolumn{5}{|c|}{38 months } \\
\hline \multirow{3}{*}{ Voltage } & Before & 375 & \multirow{3}{*}{ K-factor } & Before & 1.3 \\
\hline & After & 383.63 & & After & 1.3 \\
\hline & $\mathrm{Cmp}$ & 8.63 & & $\mathrm{Cmp}$ & $0 \%$ \\
\hline \multirow{3}{*}{$\begin{array}{l}\text { Monthly active } \\
\text { power }\end{array}$} & Before & 55680 & \multirow{3}{*}{$\begin{array}{l}\text { Monthly } \\
\text { reactive } \\
\text { power }\end{array}$} & Before & 38864.9 \\
\hline & After & 55680 & & After & 18301.1 \\
\hline & Cmp & $0 \%$ & & Cmp & $-52.91 \%$ \\
\hline \multirow{3}{*}{$\begin{array}{l}\text { Monthly power } \\
\text { factor }\end{array}$} & Before & 0.82 & \multirow{3}{*}{$\begin{array}{l}\text { Monthly wire } \\
\text { loss }\end{array}$} & Before & 2610.57 \\
\hline & After & 0.95 & & After & 1944.87 \\
\hline & $\mathrm{Cmp}$ & $15.85 \%$ & & $\mathrm{Cmp}$ & $-25.5 \%$ \\
\hline \multirow{3}{*}{ Meter loss } & Before & 184.8 & \multirow{3}{*}{$\begin{array}{l}\text { Monthly total } \\
\text { loss }\end{array}$} & Before & 2795.37 \\
\hline & After & 184.8 & & After & 2129.67 \\
\hline & $\mathrm{Cmp}$ & $0 \%$ & & $\mathrm{Cmp}$ & $-23.81 \%$ \\
\hline \multirow{3}{*}{$\begin{array}{l}\text { Monthly line } \\
\text { loss rate }\end{array}$} & Before & 5.02 & & & \\
\hline & After & 3.82 & & & \\
\hline & $\mathrm{Cmp}$ & $-23.9 \%$ & & & \\
\hline
\end{tabular}

\section{Improve the phase imbalance}

The installation of reactive power compensation device can effectively improve the phase imbalance, so that the three-phase transformer outlet imbalance has been significantly improved, while the voltage of the phase can be improved. Choose a typical station area from Lanzhou, select the two-day comparison of the voltage boosting with similar load of device putting into operation and exiting, shown in Figure 5. 


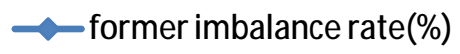

$\rightarrow$ latter imbalance rate(\%)

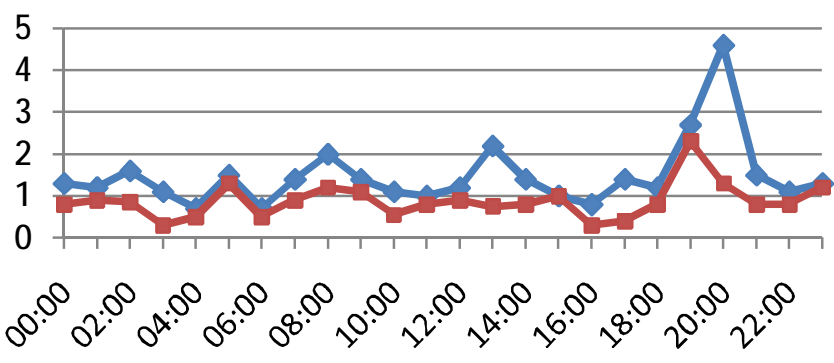

Figure 4-2. Lanzhou XiRui sands area three-phase imbalance improve comparison chart

As shown in Figure 5, three-phase imbalance can be reduced after the device puts into operation, the maximum reduction rate is $3.26 \%$.

\section{Improve the supply capacity of the transformer}

In the certain equipment capacity circumstances, the reactive power compensation improves the power factor, also increases the transport active power of grid or equipment, which can send less reactive power. The more active power can be sent calculations as follows:

$$
\Delta p=p_{2}-p_{1}=s\left(\cos \varphi_{2}-\cos \varphi_{1}\right)
$$

The 257 public stations intended to reconstruct has a total capacity of $42080 \mathrm{KVA}$. After the installation of reactive power compensation, in the capacity of the transformer equipment remains unchanged, according to the actual operating conditions, within the test areas, after the distribution network integrated energy-saving device putting into operation, the average power factor increased from 0.8 to 0.95 . According to the above formula (4-1), it can send active power $1,300 \mathrm{~kW}$ more.

\section{Reduce reactive power flow}

When reactive power flow flows in the grid, voltage will drop. Reactive power flow (load) increases, the voltage drop generated in the grid increases. Installation of reactive power compensation equipment in low-voltage side of public stage area, the whole distribution network reactive power has been optimized to reduce the reactive power losses throughout the distribution network.

\section{Conclusion}

1) Choose the mode of energy management contracting which shares benefits to organize and implement distribution network reconstruction, comparing with its own investments, it can fully enjoy tax incentives, expand funding channels and accelerate the distribution network reconstruction, increasing voltage reliability and voltage qualification rate of the distribution network while reducing consumption and loss. It provides beneficial exploration for carrying out energy management contracting, establishes a typical case and enhances the overall operational capability.

2) Through construction of the distribution network energy efficiency management platform, from three dimensions of capacity, technology and management of power grid, it achieves distribution network energy assessment, energy efficiency monitoring, energy analysis and energy efficiency regulation to provide basic support for energy saving, achieving the informatization of energy-saving service and intelligence of distribution network reconstruction.

3) Energy management contracting has its unique advantages in power grid enterprises developing 
distribution network reconstruction, it can be widely implemented in other regions. In this mode, while the completion of two indicators of electric power and energy savings of $0.3 \%$, it reduces the distribution network loss and promotes the development of grid energy service companies.

\section{References}

[1] Guoqi L, Yan Z, Dakang Z. Life Cycle Cost and Its Application in Power Grid Planning [J]. Modern Electric Power, 2009, 6: 018.

[2] Liu Jian, Ni Jianli, Deng Yonghui. Distribution Automation System. Beijing: China Water Power Press, 2003. 1-4

[3] Lei Ming. Practical application of energy management contract in energy saving service carried out by power grid enterprises [J]. Power Demand Side Management, 2008:30-31.

[4] Qi Li. Research on Method and Application of Post-evaluation Management of Distribution Project[D]. North China Electric Power University, 2012.

[5] Li Peng, Wang Xuelun. Intelligent Distribution Automation System and Information Fusion[A]. Chinese Society for Electrical Engineering Symposium, 2013. 